Universidad de Guadalajara

Derecho Global. Estudios sobre Derecho y Justicia

Año 3, núm 9, julio-octubre, 2018, pp. 37-56, ISSN: 2448-5128 e-ISSN: 2448-5136

https://doi.org/10.32870/dgedj.v0i9.165

\title{
Otro eufemismo de la verborrea represiva Franquista: La libertad vigilada. Control y supeditación social. Un ejemplo desde el país valenciano
}

\section{Another Francoist euphemism: probation (libertad vigilada). Social control and subordination. An example from de valencian country}

Ricard Camil Torres Fabra

Recibido: 15/12/2017

Profesor. Universidad de Valencia. España

Aceptado: 03/02/17

ricard.torres@uv.es

RESUMEN: El presente trabajo tiene como objetivo mostrar una modalidad de la represión franquista: la denominada libertad vigilada, o sea la excarcelación de penados antes del cumplimiento de condena. La metodología empleada ha consistido en rastrear el proceso y sus normativas mediante la consulta de fuentes primarias, contrastándolas con la escasa producción historiográfica. Hemos tenido la suerte de encontrar documentación dispersa en archivos menores del país valenciano. Todo ello conlleva que el debate historiográfico no se haya producido a la espera de nuevas aportaciones. El fenómeno de libertad vigilada únicamente se aplicaba a penados por razones políticas. Dada la magnitud de los mismos, se configuró una legislación concreta y a gestar un conglomerado de organismos dedicados a la vigilancia de los penados, que a pesar de quedar en libertad continuaban siendo considerados presos. Las razones de estas excarcelaciones venían provocadas por el inmenso volumen humano derivado de la represión franquista.

PALABRAS CLAVE: Franquismo, Represión franquista, mundo penitenciario.

ABSTRACT: This paper aims to show one the many ways of the Francoist repression: the so-called libertad vigilada, probation. This concept refers to the release of convicts before the order has been completed. The methodology used has been tracking the case and its regulations through consulting primary sources, contrasting them with the very little historiography production. A lot of the information has been found in smaller files in the Valencian Country. This means that the historical debate has not had further contributions. The phenomenon of this type of probation was only applied for political reasons. Due to their great number, a concrete legislation and new organisms dedicated just for their surveillance were created. Although being released, they were still considered convicted. The reasons of these realeases were the immense number of people derived from the Francois repression.

KEY WORDS: Francoism, Francoist repression, prison, penitentiary 


\section{SUMARIO}

I. Introducción. II. La cárcel sin muros. III. Los tentáculos de la Junta de libertad vigilada. IV. Los vigilados y su tratamiento. V. El final de la pena. Bibliografía.

\section{Introducción}

A partir del 1 de abril de 1939, el Estado Español se convirtió en una inmensa prisión (Molinero \& Sobrequés, 2003. Gómez Bravo, 2008. Rodríguez Teijeiro, 2001). No es que el número de penados no fuera escandaloso antes de esa fecha, pero el final de las acciones bélicas proporcionó un impulso formidable a la volumetría humana privada de libertad. Aunque, según fuentes oficiales, en 1940 la población reclusa superaba las 270.000 personas $^{1}-$ sin contabilizar seguramente la mayor parte de los detenidos gobernativos, presos en depósitos o prisiones municipales y niños que se encontraban en la prisión con sus madres-, se calcula que más de 500.000 personas pasaron en algún momento por campos de concentración, batallones de trabajo y todo tipo de centros de reclusión (Torres Fabra, 2013).

La política penitenciaria franquista tenía una función clara: la humillación de los vencidos y de sus familias buscando su degradación, anulación, domesticación y la sumisión total de la persona. Todo ello dirigido a acabar con el prototipo del hombre y de la mujer laicos y críticos que afloraron durante el periodo republicano, con los trabajadores que lucharon por la justicia social, y con las mujeres que comenzaron a emanciparse del modelo masculino y patriarcal imperante hasta entonces. No se debe olvidar que el objetivo fundamental del golpe de Estado del 18 de julio era reducir lo antes posible al enemigo que es fuerte y bien organizado (...) Desde luego serán encarcelados todos los directivos de los partidos políticos, sociedades y sindicatos no afectos al Movimiento, tal y como ordenaba Mola en su Instrucción Reservada, $N^{o} 1$, Base $5^{\mathrm{a}}$, del 25 de mayo

1 Estadísticas del Ministerio de Justicia libradas a la Comission Internationale contra le Régime Concentracionnaire en 1953. Publications de la Comission interlationale contre le régime concentrationnaire, Paris, Editios du Passe, 1956. 
de 1936 (Sánchez Pérez, 2013, pp. 343-346).

El caso es que esta táctica sentaría las bases de la represión que acompañaría a los avances de las tropas franquistas y, por supuesto, continuada una vez rendida la Segunda República. Ahora bien, y volviendo a la astronómica cifra de encarcelados a partir de 1939, el problema que presentaba tal volumen resulta obvio: colapso judicial, carga económica, dificultades higiénicas y deterioro de los establecimientos penitenciarios. Estos problemas se "solucionaron" por varias vías: el exterminio directo -no menos de 120.000 personas según los estudios locales fueron ejecutadas, incluyendo en este apartado toda la tipología de las muertes en prisión ${ }^{2}$-, el cumplimiento íntegro de la condena impuesta por los tribunales militares, bien acogiéndose a indultos, bien por el sistema de Redención de Penas por el Trabajo (Rodríguez Teijeiro, 2016, pp. 187-188, Gómez Bravo, 2011, p. 819), bien logrando la salida del establecimiento penitenciario al considerarse pecata minuta la sentencia o la orden gubernativa correspondiente.

Estos tres últimos casos tenían la misma finalidad: pasar a los penados a ser controlados mediante la denominada libertad vigilada ${ }^{3}$. Un estatus difícilmente explicable dado que el acceso a la libertad vigilada significaba en la

2 Asociación para la Recuperación de la Memoria Histórica. (2015). Buscador de víctimas. http:// memoriahistorica.org.es/listados-de-victimas/, consultado el 2 de diciembre de 2017.

3 Como se podrá comprobar, el término libertad vigilada resulta ambiguo. Más otro eufemismo que otra cosa, por lo que en numerosas ocasiones la referencia documental señala libertad condicional, pero podemos observar las diferencias entre ambos términos. La primera respondía a una medida de seguridad que otorgaban los tribunales militares en la cual iban expuestas las limitaciones, prohibiciones, obligaciones y reglas de conducta durante el período comprendido entre la excarcelación del penado y la fecha de consumición de la pena impuesta. La medida, en teoría, pretendía proteger a las supuestas víctimas al tiempo que buscaba la rehabilitación y la reinserción social del penado. En la práctica no era más que otra forma de control sobre las personas consideradas no afines al régimen. Por su parte, la libertad condicional era una figura jurídica que se presentaba como alternativa a una pena privativa de libertad cuya preservación venía delimitada por no incurrir en nuevos delitos o faltas, también en teoría, con la finalidad de una enmienda de rehabilitación. Esta medida se aplicaba a penas menores aplicadas a sentencias punitivas de casos casi triviales. La principal diferencia entre ambas, pues, estribaba en que mientras la arbitrariedad en que quedaba el penado o penada al pasar a la situación de libertad vigilada resulta evidente en el caso del franquismo; la libertad condicional contemplaba una norma específica para su cumplimiento: la no comisión de delito. A estas modalidades deberíamos añadir la figura de la libertad provisional, consistente en un permiso otorgado a un procesado para no entrar en prisión hasta que no se produjera sentencia sobre su caso. Al tratarse de tribunales militares y sobre todo por su carácter punitivo, rara vez nos ha aparecido esta situación. 
práctica el mantenimiento de la sentencia muros afuera de los centros de reclusión.

\section{La cárcel sin muros}

La idea de conceder la libertad provisional a penados por la aplicación de la justicia militar (Tribunales de Responsabilidades Políticas -TRP4 ${ }^{4}$ ) que comprendía a los encausados que habían cometido "delito" desde octubre de 19345, comenzó a aplicarse a partir de 1940, dando sus resultados a partir del año siguiente cuando 50000 reclusos obtuvieron la condición de libertad condicional (Serrano y Serrano, 2002, p. 42) y cuyos beneficiarios fueron los condenados a las penas más bajas y progresivamente fue ascendiendo los escalafones temporales de encarcelamiento hasta que en 1943 fue ampliándose a las condenas superiores: veinte años y un día y así sucesivamente, pero en modalidad de libertad vigilada.

Los penados extramuros, puesto que continuaban siendo penados hasta que consumieran la condena, quedaban sometidos a la jurisdicción de las Juntas Locales de Libertad Vigilada ${ }^{6}$, conectadas con la Dirección General de Prisiones. Tales juntas supervisaban el comportamiento de los implicados mediante la

4 Promulgada el 9 de febrero de 1939 y publicada en el Boletín Oficial del Estado el 13 de febrero de 1939, dictada pues al final de la Guerra Civil cuya intención no era otra que la de ajustar cuentas con los vencidos, especialmente de aquellos que hubieran apoyado la legitimidad de la Segunda República Española. En su enunciado se apuntaba que la Ley de Responsabilidades Políticas (de ahora en adelante, LRP) se hacía necesaria por la necesidad de reconstrucción espiritual y material de la Patria, además de reconocer que su objetivo era el de liquidar las culpas contraídas por quienes contribuyeron a forjar la subversión. Recordemos que los sublevados de julio de 1936 consideraban a quienes permanecieron fieles al régimen legal como los verdaderos sublevados. Se trataba, como apuntaba el propio Serrano Suñer, de la justicia al revés.

5 La LRP contemplaba la retroactividad de los actos penados, es decir, actos que en el momento de cometerse no estaban tipificados como delito, independientemente de lo arbitrario del proceso. De ahí que se incluyera la fecha de octubre de 1934, momento de los hechos revolucionarios de Asturias y Cataluña.

6 En 1977, poco antes de las primeras elecciones democráticas, el ministro Martín Villa mandó destruir los archivos de Falange y demás organizaciones del denominado Movimiento Nacional, por lo que la documentación disponible resulta magra y dispersa. Nosotros hemos tenido la suerte de encontrar el fondo de la Junta de Libertad Vigilada del Partido Judicial del distrito de Sueca, Valencia, el Libro de Actas de la Junta de Libertad Vigilada (de ahora en adelante, LAJLV), y dado que se trata de una de las fuentes más completas y cuyos sucesivos expurgos no han dañado en demasía ni la cantidad ni la calidad de sus fondos, resultan muy adecuados para lo que pretendemos esbozar aquí. Asimismo, complementaremos las informaciones pertinentes con las proporcionadas por los archivos históricos de Sueca y Cullera (Valencia) por las mismas razones. 
presentación de los mismos en el cuartel de la Guardia Civil, la comisaría de policía, el Ayuntamiento y, en casos extremos, el juzgado local o comarcal, generalmente cada quince días. Por supuesto, estaban continuamente vigilados por las fuerzas del orden, además de pasar examen médico con la finalidad que los penados no pudiesen esgrimir causas de salud para evitar las presentaciones periódicas.

La burocracia franquista, en este aspecto, construyó un laberinto organizativo vertical que constaba de la Comisión Central de Libertad Vigilada, que comprendía la representación de los organismos de justicia, seguridad, Falange, castrense y Ministerio de Trabajo. A continuación, las Juntas Provinciales y Locales. No obstante, en realidad el organismo que realmente llevaba la batuta era la Junta Local, ya que, a pesar de no poseer la potestad para sancionar, sus informes resultaban determinantes (Rodríguez Teijeiro, 2012, p. 54).

Como se desprende, a medida que las prisiones se iban vaciando mediante este sistema, el problema de controlar a tanta población ex reclusa pero penada iba alcanzando magnitudes mayores. Para afrontarlo se creó el Servicio de Libertad Vigilada, que lejos de constituir un organismo meramente penitenciario resultaba ser un ente político más ideado por la dictadura para extender sus tentáculos de poder y control social sobre la población vencida que otra cosa. Ni qué decir tiene que cualquier comportamiento no grato por parte del interfecto comportaba el retorno a la prisión.

Para acceder a la libertad vigilada había que cumplir una serie de requisitos que quedaban contemplados en el decreto del 5 de abril de 1940 en su artículo primero. Aquí se señalaba que los condenados a la pena de reclusión menor o inferiores por delitos relacionados con la rebelión marxista (sic) que ya habían cumplido la cuarta parte de la condena en los centros de reclusión penitenciarios y en los que su conducta hubiera sido intachable además de ser mayores de 60 años de edad, podían acceder a la libertad vigilada.

Ahora bien, el decreto contenía elementos limitadores como el retorno a la cárcel y, en su artículo segundo, la prohibición de residir en la localidad de 
origen en caso de proponerlo así las autoridades pertinentes. El estatus de libertad vigilada quedó ampliado por el decreto del 1 de abril de 1941, que contemplaba en su artículo primero la creación de la situación jurídica de la libertad condicional (confundiendo ambas figuras estatutarias) para los beneficiados por la Orden del 25 de enero de 1940. Esta última fue ampliada por las leyes del 4 de junio y del 1 de octubre, además del mencionado decreto del 5 de abril del mismo año, que comportaba un relativo amplio abanico de personas que podían disfrutar de esta nueva situación. Es decir, los condenados que no excedieran la pena de 12 años por el delito de rebelión en cualquiera de sus modalidades -cometido entre el octubre de 1934 y el 1 de abril de 1939- necesitaban el beneplácito de la Junta correspondiente y pasar un examen efectuado por el sacerdote de la cárcel relativo a la formación religiosa. Esto se daba siempre y cuando los condenados no pudieran crear alarma social por su regreso, según la Junta. Estos condenados pasaban a ser desterrados durante el resto del tiempo de condena a más de 250 kilómetros de distancia del lugar donde hubieran cometidos el/los delito/s o de su lugar de residencia habitual (Se puede observar un ejemplo concreto en Castelló, 2010, pp. 335-445). Como es normal, todas estas disposiciones debían pasar el primer filtro: los informes de las autoridades locales y también el informe favorable del director del instituto penitenciario correspondiente.

Como personalmente hemos podido comprobar, el estilo de estos informes tenía unas características concretas: mezclaban actividades contrarias al régimen con las propias de la libertad vigilada ${ }^{7}$. De todos modos, a pesar de que el encausado no diera problemas, siempre estaba presente su pasado para intentar reconvertir las maniobras legales en continua finalidad represora ${ }^{8}$. De esa manera,

7 En ocasiones la Junta se refería a sí misma como de Libertad Provisional o como Libertad Condicional, lo cual en la práctica tampoco importaba demasiado.

8 Siendo favorables los informes emitidos por las Juntas locales, siempre presentaban este desequilibrio: el encausado presenta buena conducta, pero se añadía como recordatorio las acusaciones anteriores. Por ejemplo, el Ayuntamiento de Sueca informaba el 10 de septiembre de 1946 al Juez Permanente del Juzgado Militar nº 17 de Valencia que (...) no consta nada (sobre José María Vendrell Rebull) en contra de su conducta, toda vez que hace vida normal, trabajando en su oficio de electricista. Eso sí, por tal de recordar al enemigo a continuación también constaba en el informe que (...), fundador del partido comunista (...) voluntario al ejército rojo (...) teniente (...) destacado como organizador (...) desafecto al régimen. Archivo Histórico Municipal de Sueca (AHMS,.Oficios Negociado Primero. 1946). Es decir, de alguna manera, por lo que respecta a las Juntas locales, el hecho de que 
la última instancia represora resultaba ser, otra vez, las autoridades locales, que mostraron la inmensidad de su potestad tanto en la emisión de informes como en el funcionamiento de la libertad condicional. Así, las personas comprendidas en la libertad vigilada no tenían capacidad ejecutiva para fijar su residencia. Por ello, a la hora de buscar trabajo $0^{9}$ o visitar familiares ${ }^{10}$ sus posibilidades de maniobra estaban supeditadas al control de la Junta de Vigilancia ${ }^{11}$.

\title{
III. Los tentáculos de la Junta de libertad vigilada
}

\begin{abstract}
Al igual que en los procesos depurativos, las gestoras locales disfrutaron de una amplia autonomía. La potestad de la Junta de Vigilancia tenía todas las atribuciones en cuanto a los penados que pasaban a la situación de libertad vigilada. La Junta se componía de un presidente, cuya figura recaía en la persona
\end{abstract}

apareciesen órdenes, leyes, decretos o disposiciones de todo tipo sobre el trato a los vencidos, no quería decir que fueran acatados en su totalidad, dado que ante evidencias como la anterior - no consta nada en contra de su conducta- las autoridades locales tendían, inexorablemente, a intentar damnificar a los derrotados. El 3 de abril de 1946, el informe sobre Pascual Pastor March no podía resultar peor para sus intereses: (...) estuvo a las órdenes del CEP (Comité Ejecutivo Popular), condenado a 6 años y un día de reclusión por auxilio a la rebelión (...). Es persona peligrosa no por acción (...) ya que se dedica sin descanso a propagar (...) todos los bulos y propagandas de las radios extranjeras. Ídem.

9 Por ejemplo, el caso del penado Leandro Montes Serrano, que, por tal de ir a trabajar de panadero a Mataró, necesitó la garantía personal de su patrón desde la localidad catalana el 22 de mayo de 1943. Archivo Histórico Municipal de Cullera (AHMC en adelante). Caja 172. Lo mismo le sucedió a José Femenía González quien, por encontrar trabajo en Zaragoza, hubo de realizar un sinfín de papeleos. AHMS. Negociado Primero. Correspondencia. 2 de abril de 1948. También cabe señalar el caso de José González López. El 3 de octubre de 1947, tuvo que pedir el cambio de zona para la libertad vigilada no sin antes apuntar su nueva dirección. Libro de Actas de la Junta de Libertad Vigilada (LAJLV), Juzgado Comarcal de Sueca, p. 9.

10 El 1 de septiembre de 1946 se ignoraba el paradero de Ignacio Cauque Losa y al mes siguiente desapareció también su primo, Juan Tomás Cauque Martínez, ambos en situación de libertad vigilada. Según las averiguaciones efectuadas por confidencias se supo que ambos se encontraban en Villarrobledo (Albacete). Estas persones fueron a visitar a su abuelo, que se encontraba a las puertas de la muerte. Finalmente, se les transfirió a la población manchega. Ídem. pp. 7-16.

11 Con todo, excepto en los casos puntuales en que la ausencia del paso del control o de infracciones eran evidentes, la Junta se limitaba a señalar que la conducta de los vigilados era buena. A partir del 3 de marzo de 1947, se apuntaba inmejorable. Tal vez los responsables de este estado de ánimo completamente desconocido en las fuentes cuando se trataba sobre los vencidos fueran la euforia patriotera desligada el 9 de diciembre de 1946 por la manifestación franquista de la Plaza de Oriente, en Madrid, contra la ONU y la previsión de una retirada de embajadores, amortiguada por la llegada el 16 de enero de 1947 del embajador argentino, además de la firma en Buenos Aires del acuerdo comercial hispano-argentino, el 30 de aquel mes. 
del juez de Primera Instancia del Partido Judicial; un abogado de Falange; el comandante del puesto de la Guardia Civil; un delegado sindical; un concejal delegado del Ayuntamiento; un delegado local de Falange; el juez municipal sustituto (en el caso de que la población no fuese cabeza de partido judicial) y un secretario, que se reunían una vez al mes, generalmente el día 2, aunque muy de vez en cuando también lo hacían de manera bimensual, el 2 y el 16 de cada mes.

La Junta local funcionaba pidiendo informes de personas con el fin de actuar con las que se encontraban en la situación de libertad vigilada ${ }^{12}$. Asimismo, se requería su opinión para conocer cuál era la impresión con tal de cambiar a un preso de estatus, si su puesta en libertad significaría causa de alarma social, si las autoridades locales se decantaban por el destierro, ${ }^{13}$ etc. Además, y lo que era más importante, la Junta pedía el apadrinamiento por parte de personas de solvencia para el régimen como requisito indispensable para poder acceder a la libertad vigilada. Es decir, además de los requisitos exigidos por parte de las diversas órdenes, leyes y disposiciones pertinentes las personas que accedían a la libertad vigilada necesitaban como paso previo de la autorización de la Junta un avalador de su gusto. De esa manera, se estrechaba el marco legal esgrimido por el Estado con el fin de ser dominado por los poderes locales. Las altas que se producían, pues, estaban reguladas por la propia Junta, lo mismo que las bajas, ya que hay recordar que el nuevo estatus se caracterizó porque extinguía la pena, no sus efectos, hasta los momentos en que otros resortes hicieron su aparición como el indulto, generalmente por vía de la Junta Provincial del Servicio. Además, la Junta poseía potestad para sancionar ${ }^{14}$, salvo en casos que necesitaban ejecución

12 Lo cual no deja de sorprender debido a que prácticamente eran las mismas personas las que demandaban información y las que evacuaban la misma.

13 En este aspecto, a las mujeres se les limitaba la posibilidad de destierro atendiendo a las necesidades de sus hijos. Por otra parte, el destierro podía ser permanente o circunstancial, es decir, con posibilidad de retorno a la localidad de residencia habitual del interesado una vez extinguido el tiempo de la pena restante, o resultar definitivo con prohibición implícita de retorno. En caso de cambio de residencia por las razones que fueren, excluyendo la expiación del destierro, el penado estaba obligado a comunicar el cambio. Si este se producía dentro del ámbito geográfico de la provincia en que residía, la petición debía realizarse a la Junta Provincial de origen y esta tramitaba o denegada el cambio, estudiando a fondo el caso si el cambio de domicilio tenía como destino Madrid, Barcelona, Valencia, Sevilla y Zaragoza, ya que al ser las ciudades más pobladas eran las que más problemas de control podían presentar.

14 Por ejemplo, el 1 de septiembre de 1946, la Junta Local de Libertad Vigilada de Cullera amonestó a Vicente 
y debían intervenir instancias superiores, aún y que para algunas cuestiones la postura de la Junta era más que respetada, como los informes para dar indultos, tratar sobre destierros, etc. Por otra parte, la Junta local también era la capacitada en primera estancia para supervisar la Tarjeta de Libertad Vigilada ${ }^{15}$.

La actividad de la Junta resultó ser bastante dinámica. No en vano un buen número de personas fueron detenidas y condenadas, por lo que pronto comenzó su actuación. Además, al contrario de lo que pasaba con la situación en las cárceles, la Junta disfrutó de una saludable posición económica dado que los ayuntamientos cumplieron sin fisuras sus obligaciones monetarias para alimentarla financieramente.

Los gastos que originaban tanto las Juntas locales como las de distritos judiciales se cubrían mediante subvenciones municipales dirigidas a tal efecto. El cálculo aplicado en el caso de Juntas de distritos judiciales se realizaba empleando una regla de tres atendiendo a la población en situación de libertad vigilada, tal como recoge el LAJLV, aunque esta cuestión estaba tipificada en las ordenanzas del Ministerio del Interior

Con todo, las Juntas se mostraron muy meticulosas con las personas que volvían del destierro, especialmente, y aunque había expirado su paso por la libertad vigilada, seguían siendo objeto de un seguimiento especial. Además, ante la falta de presentación de alguna persona en la fecha prevista, se iniciaba una inmediata pesquisa cuyo resultado casi siempre era debido a una enfermedad del encausado.

Por otra parte, a pesar de integrar la Junta local, los falangistas llevaban su control particular. Así, la Falange suecana contaba de un fichero con 116

Martínez Muñoz por falta y si continua su mala conducta se verá privado de los beneficios de la libertad condicional. AHMC. Comunicaciones, 1946, Caja 657.

15 En la práctica, la tarjeta venía a ser un carnet de identidad exclusivo para aquellas personas que se encontraban en situación de libertad vigilada, y comprendía los datos de filiación, fotografía, impresión de huella dactilar, residencia e instrucciones sobre la presentación regular a la autoridad competente. La tarjeta se entregaba al interfecto en el momento de su salida del establecimiento penitenciario o bien por la Junta Provincial correspondiente, ya que no todos los penados cumplían condena en establecimientos coincidentes geográficamente con el domicilio del preso. 
personas que habían finalizado su libertad vigilada y denunciaron a todas ellas por escuchar la radio o propagar noticias y bulos, excepto un niño de 14 años acusado de propagandista y mantener relación con los bandoleros $^{16}$.

\section{Los vigilados y su tratamiento}

En cuanto a la casuística contemplada hay que señalar que las leyes, decretos y órdenes sucesivos alimentaron el capital humano de la Junta. Esto hacía que la procedencia de estas personas fuera continuamente homogénea: penados por los sumarísimos del TRP o similares que enrolaban a toda una población sospechosa para el régimen y de la que, además, se tenía la certeza de no estar nunca en disposición de integración ya que los vencedores así lo disponían. Nosotros podemos reconstruir parcialmente la situación partiendo de testimonios orales, como el de Enrique Chulio ${ }^{17}$, precisamente por haber pasado por todos los escalafones penales: desde pena de muerte hasta la libertad condicional.

Enrique Chulio, que evitó puede ser lo peor gracias a su astucia tras haber sido hecho prisionero en el puerto de Alicante al intentar huir de España el 30 de marzo de 1939, fue denunciado después por la Falange local de haber participado supuestamente (el hecho no está probado) en el asesinato de las monjas del asilo de su pueblo. Nuestro entrevistado tuvo la suerte de que su cuñado, al tiempo que había luchado en el campo vencedor, había ingresado en la Falange y estaba bastante bien relacionado, por lo que delegó sus descargos de defensa a un capitán amigo suyo del cuerpo judicial.

16 AHMS. Falange. Caja Z. Los bandoleros a que se hace referencia eran los guerrilleros de la Agrupación Guerrillera de Levante y Aragón. El censo de la población de 1940 arrojaba un saldo de 13827 personas.

17 Durante la Guerra Civil, Enrique Chulio, socialista y ugetista, participó en la confección de la colectividad de la UGT (Unión General de Trabajadores, de tendencia socialista), enfrentada a la mayoritaria de la CNT (Confederación General del Trabajo, de tendencia anarcosindicalista), además de ser miembro del Comité Local de Cullera. Detenido tras la guerra, fue sentenciado a la pena capital, siéndole conmutada por la de 30 años y un día de prisión mayor, para a continuación serle rebajada a veinte años, después a doce, para finalmente obtener la libertad vigilada en 1945. Con el retorno a la normalidad democrática fue elegido alcalde de su localidad por las filas del PSOE (Partido Socialista Obrero Español, de componente socialdeócrata). Entrevistado el 21 de agosto de 1987. Falleció en el año 2000. 
Sin embargo, el TRP de Gandía le impuso la pena de muerte, pero logró conmutarla en tan solo 24 horas -se desprende que a cambio de un pago de favores que desconocemos- a reclusión perpetua. A continuación, y pasando los meses, consiguió los 30 años, después 20 y más tarde los 12 años y 1 día que le permitía acceder a la libertad vigilada. Tras pasar más de cinco años en prisión salió de la cárcel para reintegrarse a la vida cotidiana, pero (...) el ambiente era muy severo (sic). Antes de hablar o cuando entrabas (sic) a un casino mirabas (sic) para ver quién estaba. Los chivatos iban que volaban (sic). La Falange hacía la denuncia y enseguida tenías (sic) (...) a la Guardia Civil en casa. De todos modos, el juez que había aqui (en Cullera) no se molestaba demasiado, pero la Guardia Civil, a la mínima estaba en casa: que si donde estaba, que a qué bar iba, que si me habia ido a Francia... un malvivir. Todos estábamos vigilados y teníamos miedo porque la guerra fue muy dura y las venganzas más. Se habian hecho enemigos hasta los niños de las escuelas. Nuestras familias siempre estaban "coloreadas" y para ellos era una distinción: rojos. Ibas (sic) a cualquier sitio y sentías (sic) a alguna persona realizar comentarios que decían “¡cuánta rojez!”. Esto no era vida.

A lo más que se atrevían las autoridades era a las denuncias veladas mediante los medios de comunicación. Así, en mayo de 1941, se podía leer en la prensa que ante la ley del 1 de abril de 1941, por la cual los beneficios de la libertad vigilada a los sentenciados a penas de prisión que no excedieran de los 12 años por el delito de rebelión, provocó que unos jovenzuelos se lanzaron (sic) sobre un liberado y le producieron (sic) numerosas lesiones, motivo por el cual el Gobernador Civil afirmara que muestra a la vez que esceso (sic) de incultura, falta da caridad cristiana (...). Ante su mandato (del Estado) no cabe más que la obediencia, la sumisión y el acatamiento, sin críticas, murmuraciones, signos de desagrado o actos con tendencias a ofender de palabra y obra, que son exponentes de un estado de apasionamiento ${ }^{18}$.

Este alegato venía a cuento por la agresión de que fue objeto un condenado

18 Las Provincias, 30-5-1941.Recordemos que todavía no se había confeccionado el estatus legal de libertad vigilada aun y cuando se aplicaba como distinción de la libertad condicional. 
por el TRP de Sueca después de haber salido de prisión por parte de un grupo de jóvenes falangistas suecanos. Eran todas las medidas que la imaginación del franquismo desplegaba ante los excesos de sus cachorros, lo que redunda en lo apuntado anteriormente.

Los penados que pasaban a la disciplina de la Junta purgaban de esa manera el tiempo de reclusión que faltaba para cumplir sus condenas, pero en realidad el proceso no fue excesivamente rápido. Así, entre el 2 de abril de 1946 y el 31 de diciembre del mismo año, tomando como referencia El LAJLV, que es nuestra fuente principal, tan solo tres personas mutaron su estatus carcelario por el de libertad vigilada. En el año 1947, únicamente una persona; y para 1948, otra, y así sucesivamente $^{19}$, lo que significa que el proceso se había efectuado mayoritariamente en 1946. Veamos qué dicen las cifras oficiales:

\section{CUADRO I}

\begin{tabular}{|c|c|}
\hline \multicolumn{2}{|c|}{ EVOLUCIÓN DE LA POBLACIÓN RECLUSA EN ESPAÑA } \\
\hline \hline AÑO & CANTIDAD DE RECLUSOS \\
\hline 1939 & 90413 \\
\hline 1940 & 213640 \\
\hline 1941 & 145851 \\
\hline 1942 & 112735 \\
\hline 1943 & - \\
\hline 1944 & 48812 \\
\hline 1945 & 39527 \\
\hline 1946 & 32380 \\
\hline 1947 & 34141 \\
\hline 1948 & 33534 \\
\hline 1949 & - \\
\hline 1950 & 27285 \\
\hline
\end{tabular}

Fuente: TAMAMES, (1977, p. 324)

Como se comprueba, a partir de 1943 parece que la población reclusa ya conoció un descenso significativo. Está claro que la tendencia contemplaba

19 LAJLV. 
una mayor dedicación por parte de las Juntas de libertad vigilada. Lo que podemos asegurar, en definitiva, es que el ritmo de entrada sería bastante más sustancial antes de 1946, refrendado por los datos del Juzgado de Sueca, lo que explica también la insignificancia de llegadas a la Junta provenientes de las cárceles. Además, la fiabilidad resulta absoluta ya que hasta el 16 de octubre de 1951 no llegó la primera alta de un preso común ${ }^{20}$, aunque este colectivo no sería mayoritario en los ficheros de la Junta hasta 1953. Aun así, el 2 de abril de $1955^{21}$, casi 20 años después de iniciarse la guerra, todavía encontramos al menos a 32 personas en el distrito suecano que debían presentarse continuamente a los controles de la libertad condicional, que habían absorbido el papel del control de la libertad vigiada. Se trataba de 16 personas de Albalat de la Ribera, 7 de Almussafes, 5 de Sollana y 4 de Cullera. En el juzgado de esta última localidad pasaba lo mismo con un encausado hasta $19644^{22}$.

\section{El final de la pena}

Por lo que hace a la modalidad de abandono de la condición de libertad vigilada, dos eran las vías que lo permitían: la extinción total de condena o el indulto, como ya se ha señalado. En el primer caso, sólo contaba el tiempo como primera condición. El penado purgaba su sentencia en estatus vigilado, y una vez cumplido el término de la misma dejaba definitivamente los controles, al menos en teoría. Por el contrario, el indulto venía concedido, cuando lo era, después de un proceso burocrático. Este proceso consistía en dirigir una instancia a la Junta que trasladaba, tras las deliberaciones, informes, etc., adecuados, la petición al magistrado presidente de la Junta Provincial del Servicio -en nuestro caso, de la provincia de Valencia-, quien tomaba la resolución final.

Por regla general, el informe de la Junta era aceptado por éste, por lo que la concesión o negación del indulto provenía directamente de la misma Junta. La

20 Por lo que la confusión entre libertad vigilada y libertad condicional venía a agudizase más todavía.

21 Las Juntas Locales de Libertad Vigilada fueron disueltas por la Orden del 29 de noviembre de 1954.

22 En este caso ya no aparecen los penados en libertad vigilada de Sueca dado que, según apuntaba el secretario de la Junta local, vienen controlados por la comandancia de la Guardia Civil de esta población. (LAJLV. p. 97). 
tramitación y resolución venía a durar entre dos y cinco meses desde el momento de la presentación de la solicitud hasta la comunicación de su resultado ${ }^{23}$. El único requisito para que este fuera total, recordémoslo una vez más, radicaba en la condición de presentar un avalista que respondiera por el interesado. Además, desde el 16 de febrero de 1948, se añadió otro requisito: que la persona liberada pudiera acceder a un trabajo. En este aspecto, se hizo desde esa fecha una demanda sobre la situación laboral de las personas con el estatus de libertad condicional (LAJLV. p. 66) ${ }^{24}$.

Este problema había alcanzado unas magnitudes evidentes. Los empresarios eran bastante reacios a dar trabajo a los liberados condicionales, excepto aquellos que aprovecharon la difícil situación del penado para explotarlo más y mejor ${ }^{25}$.

Por un lado, se trataba de personas que llevaban su venganza hasta aquellos extremos, y por otra parte hay que señalar que otros, exentos de esta militancia revanchista, tenían sus titubeos por miedo a que se les pudieran relacionar con aquellas personas marcadas ya de por vida como eran todas las que pasaron por la cárcel o por los tribunales militares. Para amansar ambas posturas, el 12 de septiembre, y coincidiendo con las ya casi escasas tareas del arroz (Torres Fabra, 2005, pp. 102-104) ${ }^{26}$, apareció un bando en los pueblos ribereños que trataba de reordenar la situación: Los liberados condicionales en situación de parados y que deseen encontrar trabajo, dirijan instancia al Presidente de la Junta Provincial de libertad vigilada (...) (AHMC, Libro de Registro de Bandos, libro 993), generalmente coincidiendo con las etapas de las tareas del arroz. Además, en ese momento pasaron numerosas personas al estatus de libertad condicional (AHMC.

23 Como se desprende de los datos aparecidos en el momento del libramiento de la instancia hasta la contestación de la misma y su ejecución.

24 La Junta comunicaba en todas sus sesiones que los penados de esta modalidad poseían un puesto de trabajo.

25 A pesar de las advertencias que en tal sentido comunicaba el Gobernador Civil, animando a los penados a denunciar tales situaciones. De todos modos, no hemos encontrado que tales abusos fueran castigados.

26 El distrito judicial de Sueca abarcaba -y lo sigue haciendo - la comarca valenciana de la Ribera Baixa del Xúquer y parte del norte de la comarca de La Safor, cuya mayor actividad económica recaía sobre la agricultura, con una clara notoriedad por parte del cultivo del arroz. Posteriormente, este iría retrocediendo a favor del cultivo de la naranja. 
Negociado Central. Comunicaciones, 2. 1944). El funcionamiento cuantitativo de la Junta fue el siguiente:

\section{CUADRO II}

\begin{tabular}{|c|c|c|}
\hline AÑO & A L TAS & B A JAS \\
\hline 1946 & 3 & 18 \\
\hline 1947 & 1 & 29 \\
\hline 1948 & 1 & 7 \\
\hline 1949 & 1 & 9 \\
\hline 1950 & 0 & 6 \\
\hline 1951 & 3 & 6 \\
\hline 1952 & -1 & 0 \\
\hline 1953 & 28 & 1 \\
\hline 1954 & 0 & 11 \\
\hline 1955 & 0 & 0 \\
\hline 1956 & 0 & 87 \\
\hline TO TAL & 68 & \\
\hline
\end{tabular}

Fuente: JLVPJS.

Esta tabla reafirma que el trasvase de personal político encarcelado a resultas de la Guerra Civil se realizó antes de la fecha de la que poseemos información en nuestras fuentes, dado que, durante el tiempo transcurrido, sólo 9 personas accedieron a la libertad condicional, mientras que 87 obtuvieron la libertad total. Tal cosa significa que el escaso número de altas provenía del descenso de población carcelaria. Por otro lado, el alto número de bajas hay que apuntarlo a la gran cantidad de gente que se encontraba en estado de libertad provisional. Lo anterior queda refrendado en el caso de Cullera:

\section{CUADRO III}

\begin{tabular}{|c|c|c|}
\hline AÑO & ALTAS & BAJAS \\
\hline 1939 & 3 & 0 \\
\hline 1940 & 1 & 0 \\
\hline 1941 & 19 & 0 \\
\hline 1942 & 22 & 0 \\
\hline
\end{tabular}




\begin{tabular}{|c|c|c|}
\hline 1943 & 39 & 5 \\
\hline 1944 & 16 & 4 \\
\hline 1945 & 7 & 1 \\
\hline 1946 & 5 & $32^{2}$ \\
\hline 1947 & 1 & $39^{3}$ \\
\hline 1948 & 3 & 10 \\
\hline 1949 & 0 & 5 \\
\hline 1950 & 0 & 1 \\
\hline 1951 & 1 & 2 \\
\hline 1952 & 0 & 0 \\
\hline 1953 & 0 & 1 \\
\hline 1954 & 0 & $1^{4}$ \\
\hline 1955 & 0 & 0 \\
\hline 1956 & 0 & 12 \\
\hline 1957 & 0 & 2 \\
\hline 1958 & 0 & 0 \\
\hline 1959 & 9 & 0 \\
\hline 1960 & 0 & 0 \\
\hline 1961 & 0 & 0 \\
\hline 1962 & 0 & 0 \\
\hline 1963 & 0 & 0 \\
\hline 1964 & 0 & 1 \\
\hline $\mathrm{NC}$ & 47 & 69 \\
\hline
\end{tabular}

Fuente: Fichero del Juzgado de Paz de Cullera. Libertad vigilada.

Está claro que esto no viene a significar una mayor apertura o magnanimidad por parte del régimen. Al contrario, los elementos más peligrosos se encontraban en los cementerios, los más, en la cárcel, los menos, y un buen número de ellos en el exilio. Lo único que podemos constatar es que la realidad represora del franquismo con respecto a la disponibilidad directa de las personas se desarrolló sobre todo entre 1939 y 1944. A partir de entonces la actividad de la represión franquista fue alejándose de la Guerra Civil, aunque no de una manera acusada ni decidida, pues siempre buscó su conexión. Recordemos que la propia guerra resultó también la propia génesis del régimen. Pero la atención represora del franquismo se trasladó a la conservación del régimen dado que 
su apuntalamiento ya era un hecho. Vemos las diversas formas de las bajas del distrito judicial de Sueca con el fin de redondear esta conclusión

CUADRO IV

\begin{tabular}{|l|c|l|c||}
\hline \multicolumn{1}{|c|}{ CAUSA DE LA BAJA } & NÚMERO & CAUSA DE LA BAJA & NÚMERO \\
\hline Extinción de condena & 36 & Indulto & 33 \\
\hline Sobreseimiento & 1 & Fallecimiento & 4 \\
\hline Alta de destierro & 4 & Destierro & 1 \\
\hline
\end{tabular}

Fuente: Elaboración propia a partir del LAJLV.

En porcentajes:

\begin{tabular}{|l|c|l|c|}
\hline \hline CAUSA DE LA BAJA & $\%$ & CAUSA DE LA BAJA & $\%$ \\
\hline Extinción de condena & $45^{\prime} 6$ & Indulto & $41^{\prime} 8$ \\
\hline Sobreseimiento & $1^{\prime} 3$ & Fallecimiento & 5 \\
\hline Alta de destierro & 5 & Destierro & $1^{\prime} 3$ \\
\hline
\end{tabular}

Fuente: Elaboración propi a partir del LAJLV.

Por tanto, la libertad vigilada vino a ser otra de las herramientas represivas que empleó el franquismo. Tal vez, y conociendo sus formas de dominación, esta fuera tan efectiva como el resto de las modalidades que empleó, dado que en última instancia la libertad de cada cual o la finalización del control directo, como se quiera, no radicaba en una responsabilidad particular, más bien quedaba al capricho - por muy tipificado que estuviera legalmente- de las autoridades vencedoras, sobre todo las locales.

Nuestra información finaliza prácticamente en 1957, y ya hemos apuntado que todavía a aquellas alturas podemos encontrar un buen número de personas que estaban sufriendo los efectos represivos derivados de la victoria de los insurgentes en la guerra. Mientras tanto, y siguiendo nuestra documentación, casi la mitad de las personas que pasaron por la libertad vigilada acabaron su condición jurídica expiando totalmente su condena, lo que no significa ningún mérito para el régimen. Otra gran mayoría resultó, a la postre, indultada. Pero también hubo personas que murieron sin haber eximido totalmente su condena, aunque en un número escaso, y otros que conocieron también las humillaciones 
y penalidades del destierro.

La libertad vigilada se añadía a las ejecuciones, la prisión, la brutalidad, la humillación y tantas y tantas modalidades de represión. Configuró por sí misma una más de las variedades franquistas en su carrera para controlar a la población e imponer de esa forma su potestad sobre una sociedad desmantelada que pasaba a la órbita de un régimen nacido en la guerra y que nunca olvidó sus orígenes ni sus pretensiones. No en vano, los indultos nunca significaron amnistías -lo que hubiera significado el olvido de hechos pasados o que en el momento de cometerse no se encontraban tipificados como delitos- ni siquiera parciales ${ }^{27}$.

Eso sí, con estos mecanismos de control y represión resultaba muy difícil la aparición de una oposición de calibre peligrosa para la dictadura. De hecho, el fenómeno de la libertad vigilada era de aplicación exclusivamente política dirigida a los vencidos. No entraremos a examinar en la verborrea del régimen si la finalidad última de la libertad vigilada a la postre resultaba un favor hacia los vencidos malgré lui o si con su aplicación se pretendía más o menos intentar integrar a los penados y ex penados, independientemente de la voluntad de los mismos, porque la realidad primera y última de la aplicación de la libertad vigilada no era otra que la de domesticación social a través del conocimiento en piel propia. En

27 Los más significativos: Decreto del 5 de abril de 1940 aplicable a mayores de 60 años condenados a penas inferiores a 20 años y habiendo consumido la cuarta parte de la pena. Ley de 4 de julio de 1940, libertad vigilada para aquellos condenados entre 6 y 12 años y habiendo cumplido la mitad de la pena. Ley de 1 de octubre de 1940, libertad vigilada para los condenados hasta 12 años y un día habiendo cumplido la mitad de la pena. Decreto de 23 de noviembre de 1940, libertad para aquellos a los que se estaba tramitando expediente de liberación. Ley de 1 de abril de 1941, libertad condicional para los penados hasta 12 años de condena. Ley de 16 de enero de 1942, libertad condicional para los penados con 14 años, 8 meses y un día de prisión, y Ley de 13 de marzo de 1943, libertad provisional para los penados hasta veinte años de prisión. A estas disposiciones le seguirían los indultos de 9 de octubre de 1945 sobre Rebelión Militar, excepto para los casos de crueldad, muerte, etc. No llegó a afectar a más del 25\% de los encausados. 17 de diciembre de 1947, Ratificación de la Ley de Sucesión, que afectaba al total de penas hasta 30 días y la cuarta parte para condenados a menos de 12 años. 9 de diciembre de 1949. Año Santo, indulto general para condenados hasta 2 años y la cuarta parte para los penados a 20 años. 1 de mayo de 1952, Congreso Eucarístico, indulto general para condenados hasta 2 años, reducción a la mitad para los penados entre 2 y 6 años, reducción de una cuarta parte o un quinto para condenados hasta 25 años. y 27 de julio de 1954, Año Mariano y Jubileo Jacobeo, indulto total para condenados hasta 6 meses, reducción de pena en una cuarta parte a los comprendidos entre 6 y 12 años, la quinta a los condenados entre 12 y 20 y la sexta a los comprendidos entre 20 y 30 . Todos ellos aparecidos en su correspondiente BOE (Boletín Oficial del Estado). 
definitiva, la libertad vigilada significó una extensión de la disciplina carcelaria franquista con muros disimulados. Ni siquiera la extinción de la condena libraría al colectivo de su estigma de rojo derrotado.

\section{Bibliografía}

CASTELLÓ, G. (2010), Final de viatge. Memòries d'un gandià: amics, coneguts isaludats, Gandia, Alfons el Vell, Gandia

GÓMEZ BRAVO, G (2008), "La política penitenciaria del franquismo y la consolidación del Nuevo Estado". En Anuario de derecho penal y ciencias penales, Tomo 61.

(2011), "Claves del modelo penitenciario franquista (1936-1948)". En Revista de Estudios Extremeños, LXVII, no II, pp. 815-836.

MOLINERO, C., SALA, M., \& SOBREQUES, J. (Eds), (2003), Una inmensa prisión. Los campos de concentración y las prisiones durante la guerra civil y el franquismo. Barcelona, Crítica

RODRÍGUEZ TEIJEIRO, D (2011), Las cárceles de Franco, Madrid, Ediciones de la Catarata.

(2012), "Instituciones de control postcarcelario en el primer franquismo: el Servicio de Libertad Vigilada", en Historia Actual Online, pp. 4960.

(2016), "El sistema franquista de Redención de Penas por el Trabajo en la segunda mitad de los años cuarenta: de los presos políticos a los comunes". En Revista de Historia de las prisiones, n 2, pp. 185-205. SÁNCHEZ PÉREZ, F. (coord.) (2013), Los mitos del 18 de julio, Barcelona, Crítica.

SERRANO, R. y SERRANO, D. (2002), Toda España era una cárcel. Memoria de los presos del franquismo, Madrid, Aguilar.

TAMAMES, R. (1977) La República. La Era de Franco. Historia de España Alfaguara. VII, Alianza, Madrid.

TORRES FABRA, R. C. (2005), Autarquia i estraperlo. L'economia en un espai rural del País Valencià, Valencia, Publicaciones de la 
DERECHO GLOBAL. ESTUDIOS SOBRE DERECHO Y JUSTICIA

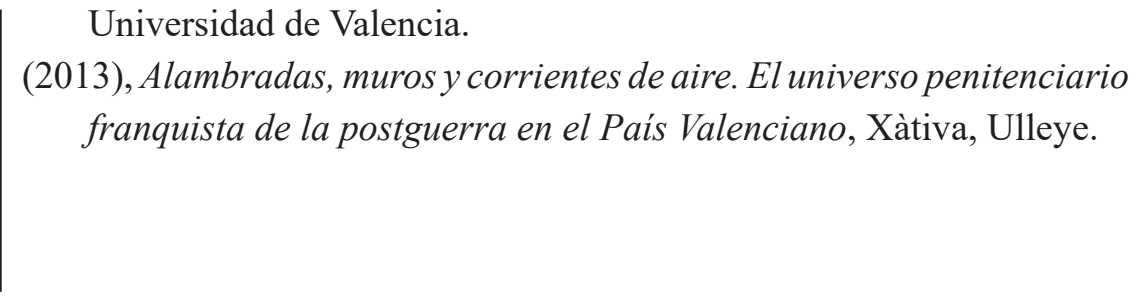

